\title{
Erratum to: Geological and Geomorphological Characteristics of High-Priority Landing Sites for the Luna-Glob Mission
}

\author{
S. S. Krasilnikov ${ }^{a, *}$, A. T. Basilevsky ${ }^{a}$, M. A. Ivanov ${ }^{a}$, and A. S. Krasilnikov ${ }^{a}$ \\ ${ }^{a}$ Vernadsky Institute of Geochemistry and Analytical Chemistry, Russian Academy of Sciences, Moscow, Russia \\ *e-mail: krasilnikovruss@gmail.com \\ Received June 21, 2021; revised June 21, 2021; accepted June 21, 2021
}

DOI: $10.1134 / \mathrm{S} 0038094621330017$

The article "Geological and Geomorphological Characteristics of High-Priority Landing Sites for the Luna-Glob Mission", written by S.S. Krasilnikov, A.T. Basilevsky, M.A. Ivanov, and A.S. Krasilnikov, was originally published electronically in SpringerLink on 8 April 2021 without Open Access. After publication in volume 55 , issue 2 , pages $89-96$ the authors decided to make the article an Open Access publication. Therefore, the copyright of the article has been changed to (C) The Author(s) 2021 and the article is forthwith distributed under the terms of a Creative
Commons Attribution 4.0 International License (http://creativecommons.org/licenses/by/4.0/, CC BY), which permits use, duplication, adaptation, distribution and reproduction of a work in any medium or format, as long as you cite the original author(s) and publication source, provide a link to the Creative Commons license, and indicate if changes were made.

The original article can be found online at https://doi.org/10.1134/S0038094621010056 